Session 3525

\title{
A Wood Engineering Design Course on Television
}

\author{
Juan J. Salinas, Don Westwood \\ Civil and Environmental Engineering, Architecture/Carleton University, Canada
}

\begin{abstract}
This paper discusses some aspects of the planning, production and delivery of a senior undergraduate engineering course offered by television. This course is normally taken for credit by senior undergraduates in civil and mechanical engineering and by architecture students. The TV version allows practicing engineers, architects and construction technologists to upgrade their knowledge in this field. Like in many engineering courses there are laboratory experiments and design assignments. Some innovative components of this effort are the collaborative approach to teaching (engineer + architect), the use of televised laboratory experiments (as opposed to live demonstration labs) and the use of information technologies for faculty-student interaction (fax, voice mail and electronic mail). The course is broadcast twice a week (three hours each time) for 12 weeks. Students in the region may watch the lectures at the broadcast time or they may record them for future viewing. Students living outside the broadcast area subscribe to a system that delivers the videotapes by regular mail every week. The course has been offered for three terms and has received favourable reviews by the students, several from many cities across Canada. Student feed-back indicates the need for a companion set of lecture notes. We are working on this and on a few other revisions necessary to update the technical material to comply with the 1995 version of the Canadian timber code.
\end{abstract}

\section{Introduction}

In 1994 the Canadian Wood Council (CWC) issued a "Request for Proposals" for the development of a television-based course on Wood Engineering Design. Three universities responded and Carleton was assigned the project probably due to the fact that our Instructional TV department has many years of experience in the production and delivery of TV courses of excellent quality. One of the authors, Don Westwood, has been doing TV courses since 1980 and at present is actively working in the production of a fifth TV course. The other author, Juan J. Salinas, developed and has been teaching a senior undergraduate course on Timber Engineering since 1978. Both authors enjoy teaching and have been recognized for their interests and achievements in education. The CWC contributed \$ 40,000 (all costs in 1994 Canadian dol$\underline{\text { lars})}$ to this project. The university contributed an equal amount, in kind, through the offices and personnel of the Instructional TV and Media Services departments. The authors estimate their contribution, in kind, to be of the same order as the figures above, bringing the total cost to around $\$ 150000$. The result is a set of 36 lectures and 2 labs with a total of nearly 40 hours of instruction capable of being broadcast over a local cable TV channel visible within a $25 \mathrm{~km}$ radius, by satellite, or deliver the tapes by regular post anywhere in Canada and the U.S. to any student officially registered in the course. Registration fees are in the order of \$200 textbook and manuals cost approximately \$100 and out-of-town students pay an extra fee of $\$ 85$ to cover mailing costs of the video tapes as well as the proctoring and supervision required for offcampus exams.. The course is a "regular" elective offered by the Department of Civil and Environmental Engineering at Carleton University as Engineering 82.422 V Wood Engineering. It usually attracts fourth 
year civil and mechanical engineering students both from Carleton and from the University of Ottawa, our sister institution in the National Capital region, as well as senior architecture students. The TV version has been offered in the summer and fall terms in 1995 and the winter and summer terms of 1996. It has attracted our regular resident students as well as a number of professional architects, engineers and construction technologists from British Columbia, Alberta, Saskatchewan, Ontario, Quebec and the Maritimes. In the following pages we will discuss some of the most important issues we encountered during this project. We see many positive aspects of this exercise which may help others interested in similar ventures.

\section{Assignment}

Upon assignment of the project the Instructional TV department formulated a contract in collaboration with CWC stipulating the finer points of the project such as funding, personnel, deliverables, deadlines, ownership, copyrights, content, liability, etc. Based on this document and with the expertise and supervision of the Director of iTV two key people were hired: a producer and a production assistant. The first had previous experience in the production of educational TV materials, in Medicine, and the second was a senior architecture student who had taken the course before and expressed great interest in the project. In addition, the Director of Instructional Media Services assigned key personnel such as director, three camera operators, switcher and other technical assistants.

\section{Planning}

Several planning meetings took place during the three-month period previous to the actual "shooting". The purpose of these meetings was to explore all the possibilities for acquisition of graphic support materials and artifacts to be used during the production. These included printed materials, graphics and charts, drawings, photographs, video clips, $35 \mathrm{~mm}$ slides, etc. This is a tremendously demanding task and should not be underemphasized. A good producer and a knowledgeable technical assistant are indispensable to compile all the materials, in the right format and with all the appropriate concerns with copyrights.

\section{Production}

Two aspects will be discussed here: the content of the course and the style of presentation. J.J. Salinas has been teaching this course (live) since 1978; his research in the field of Wood Engineering and his participation in national and international code-making organizations allows him to stay up-to-date in this area and handle the course material with confidence. Other than the production of some basic training material in Surveying, he has limited experience with TV courses. D. Westwood has been teaching structural analysis, design and construction since 1970. He has also produced at least 4 TV courses in addition to several TV series in public television dealing with Industrial Design and the History of Architecture. He has received four ACTRA awards and delivers TV lectures with ease and style. The lecture outline and overall course content was based on lecture notes developed by the authors over the many years of instruction in this area and on a textbook commissioned by CWC and developed by a group of Canadian university professors. This textbook contains an excellent Case Study which was used extensively in the course to demonstrate the use of many of the principles and applications discussed.

\section{Lecture material}

Having taught the course for many years most of the lecture material was already organized and available in electronic storage. This fooled us into believing that the production would be a breeze. It was not. The problem is that the material was organized in a format amenable for the production of letter-sized overheads. These overheads are usually shown on a large screen and the aspect ratio, font size and orientation of each page were dictated by an environment consisting of a group of viewers in a classroom with the screen located at the front and reasonably visible to even those in the back of the class. This course was meant to be seen in the students' home on a small TV screen. Under these conditions, all fonts, aspect ratio, 
orientation and content of all pages had to be revised and adjusted to the constraints of the medium. Conceptually, an easy task, involving global searches, page formatting, font re-sizing and re-editing in our favorite word processor; it turned out to be a time-consuming process. A good lesson here to be remembered. In general, we found that a 5:1 ratio of preparation:production times should be considered when planning this type of course. This includes text and graphic materials. That is preparation for shooting of already available material. The process of searching, obtaining, preparing and editing materials not already at hand would take just as much time. But this is a one-time endeavour; the benefits accrue every time the course is made available.

\section{Labs}

This was a controversial issue. Traditionally, laboratories in engineering courses are supposed to be hands-on, support the theoretical concepts discussed in class and give the students a better feeling for the course. In a "regular" (live) session of this course the students usually attend the labs and mostly end up watching a teaching assistant demonstrate an experiment with, unfortunately, small student participation. We do not believe this is the best way to learn but financial constraints have forced universities to adopt this style in many engineering courses. Since this is a distance education course, we could not find a convenient and meaningful way to bring the students to the lab. So, we brought the lab to the students. That is, we videotaped two labs and were able to capture in detail the important aspects of the experiment. This was possible, with the expertise of the production personnel, using slow motion, close-up, split screen and other techniques which allow all viewers to enjoy a first row seat at the demonstration. In addition we were able, in post-production, to add detail and commentary not possible at all during a "live" lab demonstration where only the three or four students in the first row, close to the testing machine, get a good view of what is happening during the test. We took a problem, changed it to a challenge, and came up with an excellent alternative probably better than "being there" for some students. We were also able to show several more examples, sped-up to avoid duplication and thereby prove other significant aspects of the test. For example, after testing a wood beam to destruction, one would need to show several cases before a hidden spike-knot justified what otherwise might appear as an over-conservative safety factor.

\section{Delivery}

With the exception of the two labs which were taped in the Strucures Laboratory, all lectures were recorded in a studio. A special set was designed and built with a cost of about $\$ 2500$. It consisted of a double desk to accommodate both instructors and some electronic projection equipment and a back-drop especially designed by our architecture student assistant. This back-drop consisted of a construct of wood products, systems and connections including: solid lumber, waferboard, plywood, veneer lumber, joist systems, stud walls, Wood-I joists, glulam beams and columns, trusses, etc. This provided us not only with an excellent thematic background but also with a collection of "props" and artifacts where the cameras could zoom-in to add detail to our explanations and discussions. At the end of three weeks of shooting we had produced 40 hours of instruction including 36 lectures and two labs. A summary of the contents follows:

- Wood as a resource and as an engineering material

- Mechanical and physical properties. Wood-water relationships

- The design process. Safety and reliability. Loads

- Strength. Design values.

- Wood products and systems 
- Design for members under axial loads. Tension and compression

- Flexural design

- Fastenings

- System design. Panel products

- Stressed skin panels and box beams

- Shear walls and diaphragms

- Fire safety. Maintenance and repair

\section{Issues}

TV courses have been around for many years. Here is what we believe are original an new contributions by this effort and some of the issues relevant to the production of engineering courses by TV.

1. Studio produced TV engineering courses work. Most TV courses at Carleton are taped "live" from the class-room. This works well in many areas, not in some engineering subjects. This course was produced in a studio with a minimum amount of post-production work.

2. Demonstration-type labs can be enhanced by $T V$. The camera can get closer to the experiment than many of the students would in a "live" lab. Some post-production work will enhance the value of these taped labs beyond what would be possible under "live" conditions. It can also add several other examples and thereby indicate a broad range of conditions that a single formula must cover.

3. Improved Accessibility. The "live" course is offered traditionally during one term only. The TV section is offered during all three terms making it more accessible both to resident and off-campus students. It is also more convenient for off-campus students with considerable savings in travel and parking costs for those in the region. Opens new opportunities for students in other parts of the country and it permits to reach more students. It also means absorbing set-up costs over a longer term and a wider student enrollment.

4. Enhanced learning. We believe that some of our students with learning disabilities would benefit from TV courses because they allow them to review material at their own pace and in some instances use the material for future reference.

5. Use of existing support infrastructure. We were fortunate to capitalize on the valuable assistance and direction of an experienced cadre of TV professionals in the Instructional TV and Media Services departments.

6. Communications. Face-to-face communication with students is, arguably, the best. In a distanceeducation environment this is difficult or impossible to achieve and the use of alternative Information Technologies becomes necessary. For this course we used: Email, telephone and fax. Interactive transmission of graphic information is difficult thorough these media but the use of interactive video teleconferencing is contemplated in the near future.

7. Physical environment. The course was designed to be seen on a small screen, in a small room, by a small number of students (one?). We tried to use six of the pre-taped lectures to complement a junior 
course on Civil Engineering Materials. They were shown to a class of 45 students on a small TV monitor in front of the class. It did not work. The students just did not wish to get involved. They could not see or hear from anywhere but the first row. No surprises here.

Long term impact. This TV course has already "lightened" our teaching load, allowing us to pursue other education challenges. There are some serious issues here. Will TV courses induce university administrations to reduce faculty numbers? With the reduction of faculty and elimination of courses across the universities such an endeavour would allow faculty to handle more courses. Moreover this could counter the already-experienced likelihood of dis-accreditation in some schools, particularly Architecture. TV courses could also allow schools to 'help' each other to weather such problems; students could take such courses at other institutions and simply go through a credit transfer. Maybe TV courses are not just a new-fangled technological option; perhaps they are an essential ingredient to our survival !

\section{About the authors}

JUAN J. SALINAS did his undergraduate studies in Civil Engineering at ITESM (Mexico), his graduate studies at the University of Illinois (USA) and the University of Calgary (Canada). A professor at Carleton University since 1975, he has been actively involved in teaching, curriculum development, research in Wood Engineering and international development with the United Nations in Latin America.

DON WESTWOOD did his undergraduate studies in Architecture at the Regent Polytechnic (London) and his graduate work at the Polytechnic (London). He joined Carleton University in 1971 where he has developed and taught a wide range of courses from the introductory level through graduate seminars. He pioneered the development of graphic and modeling techniques for television courses such as "The Nature and Behavior of Materials" and "Structures in Architecture" and developed the television series "Science of Architecture" and "Sense of Design" for TVOntario. He has received 4 ACTRA awards.

Both authors have received the Carleton University Teaching Achievement Award in recognition of their dedication to excellence in teaching. 